\title{
Study on the Training of College Students' Innovative Ability
}

\author{
Jing Wang \\ Department of Physics and Technology, Kunming University, Kunming, 650214, China
}

745752733@qq.com

Keywords: Students; Training; Innovative ability; Innovative talents

\begin{abstract}
In this era, talents with both knowledge and innovation are innovated. More high-quality talents with innovative thinking should be cultivated, who can adapt to social development. In order to become an innovative nation, and improve our overall national strength and competitiveness in the world, excellent innovative talents should have the characteristics of strong practical ability, deep innovation concept, high engineering technology, good comprehensive quality and wide international vision.
\end{abstract}

\section{Introduction}

It's helpful to promote students' individuality, cultivate innovative consciousness and improve the healthy development of students' personality; on one hand, educational means should be innovated to provide students with personalized learning platform by means of modern information technology. On the other hand, undergraduates may be absorbed to participate in scientific research projects to enhance students' knowledge innovation ability, constructing an innovative talent training platform for the interaction among industry, university and research, which can relieve employment pressure by enhancing students' knowledge innovation ability [1]. It is necessary to change the concept of teaching. Innovative teacher may be brought in, creating a democratic and harmonious educational environment for students with innovative ability, actively encouraging students to question and attaching importance to students' imagination. In addition, the software system construction should be strengthened. What's more, students can be encouraged to participate in social practice. [2] Teachers are the most important human resources in educational resources because the overall quality of the teaching staff directly affects the effective implementation of the innovative talent training system. The cultivation of innovative talents depends on excellent university teachers. Therefore, the construction of the teaching staff must closely cooperate with the innovative talent training program. In order to improve the teacher incentive system, a more complete year-end assessment system can be implemented, and certain bonuses can be given to teachers' innovative projects. The requirements for teachers' practical experience should be strengthened. Teachers can be trained in the corresponding jobs for a few years to increase their experience; the enterprise engineering practice experience can be linked with the teacher title evaluation; the teachers with relevant engineering experience should be given priority policies in the assessment and evaluation. Teachers with relevant experience should be accepted. It is suggested that the introduction of high-ranking and high-educated talents with engineering practical experience be increased, giving priority to full-time teachers with corporate work experience to teach or guide students to carry out relevant practices, or choose to hire those who have good technologies from the enterprise. It is unquestionable to set up the second classroom to have a positive effect on contemporary college students. But due to the lesson pressure, the second classroom may not be able to used efficiently, whose utility is difficult to reflect. In response to these situations, the idea of innovative credits came into being, and the existing credit system of the first classroom of universities is introduced in the second classroom activities to strengthen and standardize the management and guidance of the second classroom, which is good for training excellent engineers. Establishing a system of innovative credits should be based on the principle of "student-oriented", which motivates students to participate in the activities of the second classroom 
through innovative credits. It is imperative to overemphasize the form of credits and force students to participate in activities, which will eventually make students have no interest. Universities should fully mobilize the power of universities and students at all levels, adhere to the principles of goal orientation, individuation, and elective coexistence. According to the characteristics of the second classroom innovation activities, a complete set of innovative credits should be designed. Meanwhile practical and feasible credit management methods should be developed [3].

\section{Develop University-Enterprise Joint Training}

It is an important way to ensure the quality of innovative talents by developing university-enterprise joint training of students' innovation system and improving the resources for running universities through joint training with enterprises. Establishing various forms of practice bases, focusing on the use of social resources, cooperating to establish a school-enterprise joint training base and innovating practical teaching models are some main approaches to adapt to the development. It is an efficient way to change the traditional school classroom teaching form, use the resources of the school and the enterprise and combine the classroom teaching with the enterprise internship. The university and the enterprise can form a joint training steering committee to formulate plans for training programs and goals. For the lower grades, students are required to master the basic professional knowledge, while for the upper grades, on-campus curriculum should be reduced to provide a good environment for them to internships. Different types of internships can be arranged according to the professional characteristics. Under the school-enterprise joint training mechanism, more students are recommended to go to more positions for internships. If conditions permit, they can work in rotations to enable students to fully understand the different jobs of different enterprises to accumulate more experience for future development. The form of internship arranged by the school can be either diversified or simple professional, which enables students to understand the enterprise more intuitively through simulation practice. The internships can also be a field internship with different cycles, such as weeks, months, seasons, semester, school year and other different periods. It is a good way for students to understand the company and become familiar with the work according to the characteristics of different profession. Students should be encouraged to find more good business internship opportunities for themselves through the Internet and other approaches. Before entering the enterprise internship, they should correct their attitudes and understanding of the internship work, and effectively protect their rights and interests. So it is necessary to increase the introduction of corporate tutors and implement practical regulations in order to better cultivate students from both academic and practical aspects. The system will give full play the role of corporate mentor. Selecting some high-tech talents from relevant enterprises as practical teaching teachers makes students better understand the current situation of talents in society and enterprises; invite practical and experienced engineering experts in the enterprise and they can serve as part-time teachers, who will give technical guidance during students' business visits or short-term internships.

\section{Practically Improve the Conditions for Innovation}

In order to better carry out various teaching activities in the second classroom in universities and promote the cultivation of innovative talents, the system of extracurricular practice should be improved and the contents of innovative activities should be enriched to guarantee the resources of practical teaching. Besides, the construction of extracurricular activities should be paid attention to, thus building a targeted and institutionalized extracurricular practice innovation platform. The purpose of the competition is to enable college students to apply the theoretical knowledge they have learned to practice. The subject competition process can be roughly divided into: (1) entrant team formation; (2) analysis and discussion of competition topics; (3) data search and query; (4) program design; (5) physical or model Processing and commissioning; (6) writing a design summary report or research paper; (7) demonstration and review. By taking part in these evens, students can enhance their abilities, such as: innovation ability, organizational execution ability, 
teamwork ability and so on. At the same time, competitions can also be carried out at multiple levels, such as the development of faculty-level competitions, participation in provincial, national, international and other competitions [4]. Laboratory resources can be effectively used in innovative laboratories, which plays the role of laboratories in personnel training, scientific research and. In order to better stimulate students' sense of innovation and create favorable conditions for students' autonomy, research learning and even innovative experiments. Students carry out experimental projects independently, focusing on cultivating students' ability of self-practice, analyzing and solving problems. Students are encouraged to carry out innovative experiments. It is necessary to ensure that the laboratory's hardware facilities are complete, and according to the professional needs, the necessary experimental facilities are equipped to meet the needs of students' activities inside and outside the classroom. The main difference between the innovation laboratory and the general laboratory lies in the innovation of the laboratory concepts, the guidance methods of the instructors and the innovation of the management of the students system. Students must have a strong sense of innovation in research and exploration in the laboratory and create a good laboratory. Taking certain incentives can ensure the continuous development of the laboratory to innovate. Innovative classrooms require universities to change the traditional way of teaching cramming, introducing innovative ideas into the classroom, especially the second classroom, to fully mobilize students' enthusiasm and interest in learning [5]. In order to make the students who are acquainted with high-level innovative talents, more practical opportunities should be provided to students and more practical platforms should be created. Students should participate in more practical activities, and various scientific research projects, turning it into a platform for developing students' personality. Students should be encouraged to explore a combination of theories and practice to better enhance their interest in research [4]. Make sure students have sufficient guidance to enable themselves to receive systematic science training, to avoid the blindness of students participating in activities. Thus they can be purposefully guided under scientific guidance to conduct research in a targeted manner is important for the development of students and universities.

\section{Tap the Potentials of Students}

Through the mechanism system construction and innovation platform construction, a good environmental condition should be created in the university to protect students' popular science activities, stimulate students' interest and promote students' development. It is suggested that a project-oriented operation mode with scientific research projects as the mainstay should be adopted. In order to realize the boosting role of the second class, scientific activities should be carried out in line with the interests of students under the principle of autonomy and voluntarism. Student associations play an important role in the university and can improve the subjective initiative, cooperation and creativity of colleges and students. It is a stage for college students to tap their potential. At the same time, it is also an effective carrier of communication culture [5]. The university must have a set of methods for the management of student associations, and introduce relevant systems. Under the guidance of the instructors, give full play to the students' independent innovation ability and carry out active and healthy series activities. Support and encourage students' research teams to actively seek and undertake social projects and solve practical problems. It also includes independent innovation practice projects that the relevant departments of the school need to study and solve practical problems and students based on their own scientific and technological innovation ideas. The project team is encouraged to use the channel resources of the university's professional teachers and alumni, based on their own scientific and technological innovations and scientific research capabilities, to contact the company extensively, to find partners, and to undertake enterprise R\&D projects. Students can also choose their own topics, pass the school-level review, obtain funding for the project after the project is established, or provide professional research topics by professional teachers, and form a project team to undertake project research and development. 


\section{Conclusion}

Through the construction of the second classroom boosting system, the docking with the first classroom will be realized, which will become an effective extension. It can strengthen students' awareness of engineering innovation, stimulate students' interest in engineering innovation, enhance students' engineering innovation ability, and enhance students' responsibilities, consciousness and dedication. The above-mentioned curriculum system construction and practical teaching system together constitute the two-wheel drive of the cultivation of innovative talents in China's universities so that the second classroom education can develop and make achievements, becoming an effective support for the cultivation of innovative talents. Eventually, an operational mechanism will be explored for the development of innovative talents to be suited to the needs of the country, society, and themselves.

Based on the analysis of the mechanical theory as the foundation, designed the soccer robot pick the ball institutions optimal design process, found aim function, select design variables and the corresponding optimization algorithm to optimize a complete set of institutions. At last through the test to get the final performance parameters of the institution. Experiments show that the system has higher accuracy and stability, the new optimize pick the ball have design basic requirements, and achieved good ideal control effect.

\section{References}

[1] Chenxi Yin. Exploration of Talent Employment Training Mode in Innovative universities in the Micro-age [J]. Cooperative Economy and Technology, 2015, (3): 104-105.

[2] Ling Gan. Research on Talent Cultivation Model Based on Talent Evaluation System [J]. China Adult Education. 2015, (2): 42-44.

[3] Congli Yao, Baoping Ren. Cultivation of Innovative Talents in Foreign Universities and Its Enlightenment to China [J]. China University Teaching, 2008, (9): 91-94.

[4] Dong Nie, Xizhe Zhi. Comparative Analysis of Innovative Talents Cultivation in Chinese and American Universities [J]. Journal of Northwestern Polytechnical University, Social Sciences Edition, 2011, (3): 86-89.

[5] Min Wu. Basic Thoughts on Cultivating Innovative Talents in Chinese Universities [J]. Chinese Journal of School Education, 2011, (12): 10-13. 